\section{Re-designing the service experience in the value co-creation process: an exploratory study of a healthcare network}

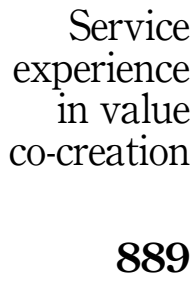

Francesco Schiavone

University of Naples Parthenope, Naples, Italy and

Paris School of Business, Paris, France, and

Daniele Leone, Annarita Sorrentino and Alessandro Scaletti

University of Naples Parthenope, Naples, Italy

\begin{abstract}
Purpose - The study aims to provide an exploratory investigation of the magnitude of the customer-centric approach in the specific area of healthcare as a contribution to the scarce and preliminary literature on this topic. In particular, it explores the role of sharing economy-based (SE-based) platforms as an experiential touchpoint to co-create value within different levels. Specifically, the purpose of the study is threefold. First, it aims to address the service experience innovation in healthcare with a customer-centric approach. Second, it seeks to define the role of the SE-based platform as a touchpoint to redefine business processes, and third, it measures the co-created value within the network when redesigning the service experience.

Design/methodology/approach - To address the research question, the authors proposed an analysis of service innovation and customer centricity in healthcare networks by using the case study of Saluber, an SEbased platform that offers logistics services for non-emergency medical transportation in the Campania region (south of Italy). By using a qualitative approach, the authors analysed primary and secondary data from multiple sources of evidence.

Findings - The results show that a customer-centric approach based on the SE-based platform can improve the customer experience and help to redesign and expand the business processes of healthcare organisations. A multilevel model demonstrates the possible service innovations that use SE principles that can co-create value for the customer (micro level), for the healthcare network (meso level) and for the community (macro-level).
\end{abstract}

Research limitations/implications - This study provides managerial implications for the players who intend to take advantage of the possibilities offered by service innovations developed by the health and social organisations in the network. The SE-based platform helps redefine business processes to improve clinical and financial outcomes and improves the overall customer experience within this network.

Originality/value - This study allows new and important reflections from ethical, social and managerial points of view and underlines how digital platforms act as a support for healthcare services, not as a substitute. Keywords Customer centricity, Sharing economy (SE), Service experience innovation, Value co-creation, Healthcare network

Paper type Research paper

(C) Francesco Schiavone, Daniele Leone, Annarita Sorrentino and Alessandro Scaletti. Published by Emerald Publishing Limited. This article is published under the Creative Commons Attribution (CC BY 4.0) licence. Anyone may reproduce, distribute, translate and create derivative works of this article (for both commercial and non-commercial purposes), subject to full attribution to the original publication and authors. The full terms of this licence may be seen at http://creativecommons.org/licences/by/4.0/ legalcode

This research was funded by the Parthenope University of Naples within the research program 2015-2017.

The authors are grateful to Guido Bourelly, CEO of Saluber, and his team for the interviews and the access to corporate information.

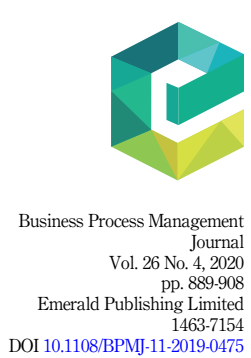

Revised 7 April 2020

Accepted 28 May 2020 
BPMJ

26,4

890

\section{Introduction}

Enhancing and innovating the service experience for customers represents a key priority for companies to survive and compete more effectively (Verleye, 2015; Lemon and Verhoef, 2016; Voorhees et al., 2017). Specifically, the challenge is successfully implementing the service experience in value co-creation processes starting by understanding customer needs (Nadeem et al., 2020; Homburg et al., 2017; Shah et al., 2006). According to the servicedominant logic (Vargo and Lusch, 2004), the service experience is designed to assemble a set of elements (physical artefacts, technology-enabled systems and the actors involved in each activity) along the customer journey to co-create value for customers and all the actors involved (Verma et al., 2012). Therefore, firms cannot expect to design experiences that follow standardised outcomes. They can only design situations that better support customers in cocreating their desired customer experiences (Forlizzi and Ford, 2000). As stated in a report from KPMG (2018), "It's one thing to say you have put customers at the heart of your business. It's much harder to make sure you have actually done it".

To this end, one of the latest research streams explored by scholars in service management studies is the use of digital technologies as enablers of value co-creation in complex service industries (e.g. Breidbach and Maglio, 2016; Mele et al., 2018; Ramaswamy and Ozcan, 2018). Recently, scholars have argued that organisations increasingly rely on developing digitalisation capabilities to find new forms of experience and co-create value with their customers (Lenka et al., 2017). Within this domain, advanced digital technologies and innovative business models are becoming the key to designing new ways to experience services. Among them, the sharing economy (SE) is rising globally in terms of user numbers, service providers and innovative practices by defining new business models and collaborative networks in different service contexts (e.g. transportation, accommodations and healthcare) (Gummeson and Mele, 2010; Romero and Molina, 2011; Habibi et al., 2017; Wilhelms et al., 2017). Other scholars analysed how the SE creates new trends by using coworking spaces to improve entrepreneurial performance through the learning processes among different coworking-users (Bouncken and Reuschl, 2018).

From the customer perspective, still other scholars explored the relational benefits that drive customer loyalty in SE services (Yang et al., 2017). Frankenberger et al. (2013) focused their research on network configuration and customer-centric approaches to improve the performance of open business models. However, existing studies remain very few and fragmented, and none of them analyses the SE models to enhance the customer experience in service industries. Most of these empirical studies are limited to the role of advanced technologies (e.g. apps) as tools to become customer-centric, accelerate the relationships between the firm and customers and to co-create value for both (Sheth et al., 2000) by creating positive results in terms of market reach and acceptance (O'Hern and Rindfleisch, 2010); furthermore, these studies produce few results regarding value co-creation for customers (end-users), firms (Carbonell et al., 2009) and society.

Additionally, in some specific contexts such as healthcare, this topic is particularly innovative because these contexts are more strongly oriented towards customer care rather than towards the customer experience (Omachonu and Einspruch, 2010; Iyawa et al., 2016). However, the healthcare industry is currently experiencing a technological transition characterised by an acceleration of innovation processes in all fields (Skaria et al., 2020), and the key element of this emerging paradigm is SE platforms supported by advanced technologies (e.g. the internet of things (IoT), virtual reality, information and communications technology (ICT), geo-localisation, etc.).

This background forms the basis for our motivation to explore the topic of this paper, namely, how a customer-centric approach oriented to the customer experience contributes to co-creating value at different levels, particularly within service industries such as healthcare through the use of the sharing economy. Our research question is "How does the SE redesign 
the service experience and create value in a healthcare network?" To answer this question, an analysis of the service innovation and customer experience in healthcare was conducted by using a case study of Saluber, an SE-based platform that offers integrated services for nonemergency medical transportation in the Campania region (south of Italy). The results show that SE-based platforms can improve the customer experience and help redesign and expand the business processes of healthcare organisations through a value co-creation process. A multilevel model demonstrates that the service innovations that use an SE platform to allow the co-creation of value for the customer (micro level), the healthcare network (meso level) and the community (macro level).

This research extends the knowledge in the service management field (Vargo and Lusch, 2004; Breidbach and Maglio, 2016; Mele et al., 2018; Ramaswamy and Ozcan, 2018) by analysing the relevance and effects of co-creation through SE-based digital platforms in an original context by offering theoretical and managerial insights. From a theoretical perspective, this study contributes to the service management literature by integrating the characteristics of the SE with the different purchase stages (pre-purchase, purchase and post-purchase) of the customer journey, as developed by Lemon and Verhoef (2016), which adds novelty to our research because these two points of view were formerly disconnected. This contribution offers a new perspective on the role of the SE in the value co-creation process (Zhang et al., 2018), with a specific focus on service industries such as healthcare (Omachonu and Einspruch, 2010; Iyawa et al., 2016). Managerial implications emerge that support the innovation of healthcare services in terms of the network effects of public health and redesigning business processes for healthcare organisations also from a social service perspective.

The paper is organised as follows. Section 2 reviews the relevant literature on service experience innovation and the customer-centric approach for the value co-creation process. Section 3 describes the research methodology, including the case study analysed and the research setting. Section 4 presents the study results. The final section discusses the findings and the implications of our study. Limitations and future research are analysed in the conclusion.

\section{Literature review}

\subsection{From customer centricity to the service experience}

Customer centricity considers customers' needs as the starting point for designing and implementing unique and satisfactory service experiences (Yim et al., 2019). Customers' engagement in service experience co-creation is a critical path to becoming customer-centric; it not only helps companies deliver services that meet customer needs, but also assumes a critical role in supporting innovation processes and co-defining new services that can sustain companies' competitive position (Alam, 2006; Chesbrough, 2017; Yim et al., 2019). The first step in being customer-centric is considering customers' inputs as the starting point for value co-creation along the journey (Lemon and Verhoef, 2016; Rindfleisch and Im, 2019) and improving their experiences to promote differentiation and customer loyalty (Zomerdijk and Voss, 2010). This approach is not a marketing concept, but it implies new business models and new co-creation processes that embrace the complexity of the entire company (Ferraresi and Schmitt, 2006). As such, firms may design situations that better support customers in co-creating their service experiences by assembling single elements (physical artefacts, technology-enabled systems and the actors involved in each activity) to co-create a complex but unitary experience through interactions between customers and providers across different touchpoints (Verma et al., 2012).

A service experience designed in this way should be able to produce positive reactions in terms of cognitive, emotional, behavioural and sensorial feelings during the entire customer journey from booking to the return home. The focus on the customer journey as a starting point to design innovative customer experiences emphasises the importance of creating a holistic experience and lean processes and adopting a cooperative approach in which customers and providers are co-innovators across the entire network (Gummesson, 2008). 
BPMJ

26,4

892

Richardson (2010) defined the customer journey as a "diagram that illustrates the steps and touchpoints that customers go through in engaging with companies" from the first interaction with the firm to the period after consumption (Lemon and Verhoef, 2016). Lemon and Verhoef (2016) attempted to map the journey with three main stages as follows: the pre-purchase stage (when need/desire arises and people start to search for and consider alternatives), the purchase stage (when people choose, order and pay) and the post-purchase stage (the moment of truth when people consume and then may express satisfaction or dissatisfaction). For each stage, the authors identified the following four categories of the touchpoints to use: brand-owned touchpoints, which include all the tools used and supplied by the firm (e.g. advertising and websites); partner-owned touchpoints, which are designed and managed by the firm's partners (e.g. mobile applications); customer-based touchpoints, which are tools that firms cannot totally control because they are managed spontaneously by customers (e.g. word of mouth, forums and blogs); and social touchpoints - chiefly, external review platforms (e.g. onlinemedicalcare. org) - that have the power to influence customer decisions at every step.

The customer-centric approach is particularly innovative and interesting to observe in the healthcare context because a majority of the public healthcare systems are more oriented towards customer care than towards the customer experience (Omachonu and Einspruch, 2010; Iyawa et al., 2016). A first attempt to change this approach is being verified with the implementation of new services to help seniors regain their independence by providing new forms of mobility to the people who live in underserved areas and by bridging public health gaps in areas. A great example is Uber Health in the USA, which was created to remove the transportation barriers that cause medical appointment cancellations. It offers transportation, caregivers and staff to manage appointments and home assistance.

In healthcare, innovation has been defined as "the intentional introduction and application within a role, group, or organisation of ideas, processes, products or procedures, new to the relevant unit of adoption, designed to significantly benefit the individual, the group, or wider society" (Länsisalmi et al., 2006). Among the different types of innovations, process innovation best fits with the customer-centric approach because it involves the implementation of a new or significantly improved production or delivery method (Iyawa et al., 2016). This approach includes significant changes in techniques, equipment and/or software. The customer does not usually pay directly for the process, but the process must deliver a product or service and manage the relationships with various stakeholders (Omachonu and Einspruch, 2010).

\subsection{From service innovation to value co-creation: the role of a sharing economy}

As argued previously, the service literature focuses on the importance of innovating managerial processes through a customer-centric approach to achieve and maintain a sustainable competitive advantage. This customer-centric approach plays an important role in co-creating a valuable experience (Prebensen and Foss, 2011; Mcmanus, and Ardley and McManus, 2019). According to these authors, when a customer engages in active participation, he/she is co-creating his/her own experience and the company becomes a provider with which the experience is co-created. From the service-dominant logic perspective, there is an interactive nature of value creation; the customer is considered to be a co-creator of value (Vargo and Lusch,2008). Ranjan and Read (2016) coherently proposed the experience as a value co-creation dimension and argued that active participation (before, during and after consumption) and physical and social interaction produce an experiential value in use. Prebensen et al. (2013) emphasised that experience becomes a co-creating value driver because the customer is personally involved in the presumption (Prebensen and Foss, 2011).

In this sense, a company can interact with its customers and gain value from these customers through continuous interactions during the journey (Barile et al., 2014; Lemon and 
Verhoef, 2016). The new concept of value is increasingly related to the response generated from inter-organisational relationships, and the prefix "co-" indicates the cooperation among stakeholders and emphasises individual contributions (Troisi et al., 2016). Traditionally, the value for customers has been considered from a utilitarian perspective as the utility derived from a certain product or service (Zeithaml, 1988; Tellis and Gaeth, 1990). By contrast, other authors have represented a more complex model of perceived value that comprises both utilitarian and hedonic dimensions to measure the value construct (Holbrook and Hirschman, 1982). This multidimensional framework shows that value is perceived not only as a trade-off of benefits and sacrifices (rational perspective) but also as a consumption experience that positively or negatively impacts feelings and emotions (experiential perspective).

Consequently, consumer value may not reside in the product/service purchased, in the brand chosen and/or in the object possessed, but in the consumption experience derived therefrom. This approach implies a more personal evaluation of perceived value that might depend on situational and contextual factors (Zeithaml, 1998; Sanchez-Fernandez and Bonillo, 2007). In fact, from an experiential perspective, the concept of perceived value has been broadly used in the service context, in which intangible factors are subjectively perceived. However, when value is co-created along the customer journey, there is a value for customers, for companies and for all stakeholders in the network (Gummesson, 2008).

In recent years, the value creation for consumers, companies and networks has been facilitated by various technologies (e.g. mobile applications, cloud computing, artificial intelligence) (Kannan and Li, 2017; Huang and Rust, 2017; Belk, 2013) that are used together with open business models such as an SE (Frankenberger et al., 2013; Habibi et al., 2017). An SE refers to "a socio-economic system enabling an intermediated set of exchanges of goods and services between individuals and organisations which aim to increase efficiency and optimisation of under-utilised resources in society" (Munoz and Cohen, 2017), generally through ICT. Thus, this open business model could refer to a service experience co-created through the interactions of providers and consumers. Recent scholars investigated the role of value co-creation in an SE, with an examination of consumers' willingness to pay a premium price (Zhang et al., 2018), in contrast with the perception of cheaper provisions of goods or services. However, Dreyer et al. (2017) analysed collaborative consumption business models as examples of an SE, which are particularly important because of their novelty and potential to disrupt established industries and markets. In these directions, this phenomenon has become popular, and many SE-based platforms have been created by following Uber and Airbnb models (Miller et al., 2016).

From a theoretical point of view, technology-based experience providers can be viewed from different perspectives (e.g. transformative service research (TSR) or service-dominant (S-D) logic). TSR analyses how the relationships between the providers and stakeholders of an experiential network (e.g. providers, partners and consumers) influence the outcome value created for both (Anderson et al., 2013). Additionally, according to the S-D logic, value cocreation should impact the stakeholder network system (Vargo and Lusch, 2016; Ramaswamy and Ozcan, 2016; Brodie et al., 2016), and SE platforms could help the exchange of information among different stakeholders (e.g. providers and customers) at different levels within the network.

From a managerial point of view, these service innovations tend to affect not only final consumers but also a range of other stakeholders that appear in various ways along the journey (e.g. technology providers, commercial partners and consumers). To implement a successful experience-based process, an integrated value co-creation approach is required, particularly a process oriented towards the value created at the micro level (e.g. consumer), the meso level (e.g. network) and the macro level (e.g. community). 
BPMJ

26,4

894

\subsection{Theoretical speculation}

This study attempts to extend the service management literature by conducting a service innovation study that considers the use of an SE-based platform as an enabler of value cocreation at different levels (micro, meso and macro). As affirmed by Gummesson and Mele (2010), interaction and co-creation in networks strive to improve service systems through a better matching among resources, processes and outcomes. Thus, the exchange of value among providers and customers would be helpful for the best application of new technologies and should be welcomed and encouraged (Payne et al., 2008; Vargo et al., 2008; Ramaswamy and Ozcan, 2018). Digital technologies offer different benefits to all players in terms of the speed and security of information (Hashem et al., 2016; Lenka et al., 2017). Moreover, information derived from an SE-based platform helps actors to develop more suitable business approaches and analyse industry competitive trends, opportunities and threats. For instance, the exchange of value has become essential in the development process in the healthcare industry; indeed, the use of ICT solutions guarantees the fluidity of communication that involves public and private actors (e.g. customers, physicians and policy makers). The World Health Organisation (WHO) contends that to promote and guarantee greater health and well-being in a sustainable way, the public health approach must involve working with other sectors to strengthen and integrate public health services and reduce inequalities. Thus, SE-based platforms represent a great example of how a virtuous network of private and public players may overcome the service gap derived from a public healthcare management system. In Italy, for example, where healthcare is entirely public and its management is decentralised to the single regions, private organisations using SE-based platforms may help regional systems in reaching all citizens.

In addition, digital health is changing the concept of well-being in daily life (Zainuddin et al., 2013). Currently, the health research and innovation in the field of new technologies is very broad and leads to the creation of new global markets. For these reasons, the health business model will be tailored to become more customer oriented (Robbins et al., 2013).

By drawing on the three different purchase stages (pre-purchase, purchase and postpurchase) of the customer experience conceptualised by Lemon and Verhoef (2016), we can develop some theoretical speculation about how SE-based platforms can support the innovation of the service experience and co-create value. We adopted Lemon and Verhoef's (2016) study because it is one of the most informative conceptual frameworks in the service management research regarding the different steps of the customer journey.

For these reasons, the support of SE-based platforms for value co-creation in service management can be resumed in two directions. First, it can improve customer satisfaction (micro level) by helping to make several benefits (e.g. reliable services) and outcomes (e.g. traceability of the system) available during their pre-purchase stage of the service experience. The digitalisation of information is increasingly improving data collection and making it more difficult to manage and understand as a whole. Firms can more proactively design innovative solutions (e.g. innovative touchpoints) to increase process quality and to meet customer needs during the purchase stage.

Second, each actor involved in the network (meso level) must adapt his/her tactics and business processes and even redefine his/her services to quickly seize new opportunities for managing the value and sustainability of digitalisation. Thus, business process redesign also depends on the use of ICT-based solutions (especially data interchange) to create business relationships. Organisations increasingly rely on developing digitalisation capabilities to find new forms of interaction and co-create value with their customers during the purchase and post-purchase stages. This final step is fundamental to redesigning the service experience from a value co-creation perspective to create a collaboration system between organisations and people within the community (macro level). 


\section{Method}

To answer our research question, we use the case study method as a research approach (Eisenhardt, 1989; Yin, 2013) to develop a multilevel model regarding the effects of co-creation through SE-based digital platforms in the service experience. Regarding the choice of the case, we respected the criteria of the research purpose. Saluber is an SE-based platform that offers logistics services for non-emergency medical transportation in the Campania region (south of Italy). The case study method is convenient when the form of the research question is "How?" (Yin, 2017). Because of the peculiarity of the case and the absence of a pre-existing theoretical framework, an exploratory research design was structured (Meredith, 1998; Yin, 2013); furthermore, we do not create propositions and hypotheses (Mills et al., 2009).

\subsection{The case of Saluber: background and setting}

This research explores the healthcare network managed by Saluber, a company that specialises in health logistics services, via a digital platform based on SE principles. As described on the platform's official webpage, "Saluber is a digital platform that wants to help your business improve the way you manage your client's rides" $\mathrm{https}$ :/www.saluber.me/en/home. This digital app was developed by the new-co Bourelly $4.0 \mathrm{SRL}$, which is devoted to presenting innovative projects and was awarded the SMAU 2018 innovation prize. Although this SE platform has not yet been put on the free market because it is currently being tested in the Campania region (south of Italy), the Saluber app has been approved by Bourelly Health Services (the app's first logistic partner). The app allows users to book, geo-localise and follow the entire customer journey and the service performed through a tablet or a mobile phone. It provides three types of services, namely, medical transport, disabled transport and home assistance.

Thus, through this sharing of means, this innovative solution places onto the same network different organisations that on their own, could have difficulty managing the customer journey and that do not provide the same services. Specifically, the network created by this sharing economy platform comprises (1) "intermediary centres" that include different types of healthcare organisations, such as private clinics or pharmacies; (2) "carriers" that are intended as companies with a vehicle fleet for non-emergency medical transport or disabled transport; and (3) "healthcare professionals" such as doctors, physiotherapists or nurses. To manage the customers' requests, the adopted criterion is related to the vehicle/healthcare professional closest to the request. Because of a technology based on geo-referencing, users, whether consumers or businesses, can conveniently book the interventions that they need at their preferred intermediary centres and receive the chosen service directly at home.

\subsection{Research structure}

Through a qualitative research approach based on primary and secondary data, we used multiple sources of evidence for the triangulation of data (Yin, 2017), and we organised the case study analysis into four phases. We collected information from (1) archival records and physical artefacts (e.g. digital platform characteristics) provided by the official website at https://www.saluber.me/, (2) personal interviews, (3) participant observations and (4) online documentation such as reports, statistical data and specialised press articles (Table 1).

As a primary source of data, we conducted 15 interviews with the various actors involved in the network. Through a semi-structured questionnaire, we requested information on the three main Saluber actors (the founder, the platform developer and the key account manager), three intermediary centres, three carriers, two doctors, one physiotherapist and three customers who used the healthcare services (Table 2). The personal interviews comprised open-ended questions to collect the perceptions about the usage and benefits of an SE-based platform in the healthcare network. Each conversation typically took $60 \mathrm{~min}$. All interviews were audio-recorded, transcribed verbatim to facilitate the analysis and anonymised.

\section{Service \\ experience \\ in value \\ co-creation}

895 


\begin{tabular}{|c|c|c|c|}
\hline \multirow{3}{*}{$\begin{array}{l}\text { BPMJ } \\
26,4\end{array}$} & \multirow{2}{*}{ Constructs } & & \\
\hline & & & $\begin{array}{l}\text { The complexity of the healthcare network in terms of the variety of } \\
\text { stakeholders and interconnectedness of services } \\
\text { The redesign of healthcare organisations' business processes via an SE } \\
\text {-based platform }\end{array}$ \\
\hline & $\begin{array}{l}\text { Archival records and physical } \\
\text { artefacts }\end{array}$ & (1) & $\begin{array}{l}\text { Official Saluber trade press, platform technical characteristics, range of } \\
\text { services, customer reviews and statistics }\end{array}$ \\
\hline \multirow[t]{2}{*}{896} & Personal interviews & (1) & $\begin{array}{l}\text { Questions about the conditions and consequences of new technology in } \\
\text { customer transport }\end{array}$ \\
\hline & Participant observations & $\begin{array}{l}(2) \\
(1)\end{array}$ & $\begin{array}{l}\text { Questions about redesigning business processes } \\
\text { An author spent one month (July 2019) in the start-up to participate in } \\
\text { Saluber activities }\end{array}$ \\
\hline of evidence & $\begin{array}{l}\text { Online documentation } \\
\text { Source(s): Authors' research }\end{array}$ & (1) & Reports, statistical data and specialised press articles \\
\hline
\end{tabular}

\begin{tabular}{lllc}
\hline \multicolumn{2}{l}{ Sample of the key informants } & & \\
Group & No & Figure/role & No. of interviews \\
\hline SE platform & 1 & Saluber founder & 3 \\
& 1 & Saluber platform developer & \\
Organisations & 1 & Saluber key account manager & 6 \\
Professionals & 3 & Intermediary centres & 3 \\
& 2 & Carriers & 3 \\
Users & 1 & Doctors & 15 \\
Total & 3 & Chysiotherapist & \\
Source(s): Authors' research & &
\end{tabular}

Afterwards, one of the authors spent a period of one month (July 2019) in the field to participate in Saluber activities and to record observations and data. The aim was to understand the service design and how this process could contribute to the co-creation of value at different levels (micro, meso and macro). As secondary sources, several media publications and official reports from January 2019 to September 2019 were also analysed to understand the impact of Saluber solutions and their influence in co-creating value in the healthcare system.

The analysis practised an iterative and inductive approach. The inductive theory based on qualitative data is considered to be appropriate in an understudied empirical environment in which there is relatively little prior work (Bansal et al., 2018). The multiple data elements furnish a stronger demonstration and consistency of the key objectives of the case study. Although multiple sources of evidence (e.g. personal interviews and online documentation) are different and independent, their combination can be fundamental to scholars as complementary perspectives of the phenomenon may be produced. Therefore, personal interviews, archival records, media publications and other evidence were triangulated and analysed through a thematic analysis (Braun and Clarke, 2006). We considered the research question to code, and we associated the emerging themes based on the space within each source of evidence (e.g. personal interview). The software NVivo 8 was implemented to identify the emerging themes through a word frequency analysis. However, argument modelling that uses thematic analysis might result in some words being associated with more than one emerging themes; thus, we screened the emerging elements and synthesised the findings into the following three main points of view: (1) the customer experience at the micro 
level, (2) the business processes for the network of healthcare organisations (HOs) at the meso level and (3) the social service experience within the community at the macro level.

Finally, the evidence is classified according to the specific steps of the value co-creation processes to which they refer. To clarify the research context and the main services provided by the SE-based platform, the proposed research method also explains and strengthens the key information of the selected case study in the next section.

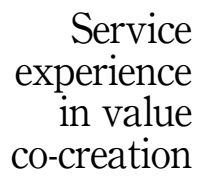

897

\section{Findings}

The heterogeneity of users and services that characterises a healthcare network is clearly reflected in the SE-based models. Accordingly, several actors (e.g. physicians, HOs, customers and carriers) in the community can be classified and positioned at various levels. This section presents an overview of the relevance and effects of co-creation at different levels (micro, meso and macro) through SE-based platforms in health service experiences. Healthcare services are improved through the different uses of the SE for each actor involved in the network. The following evidence also shows how the service innovation co-created value by (1) mapping the strategic stages of the customer experience and identifying the touchpoints, (2) redefining the business processes for HOs and 3) arranging a social service experience from a value co-creation perspective within the community. At the end of this section, Figure 1 illustrates how an SE redesigned service experience identifies the various stages of the customer journey from a value co-creation perspective.

\subsection{Effects of co-creation through a sharing economy at a micro level: the customer experience}

The attention to customers' experience during their entire journey is increasingly important in a network created by a digital platform based on the principles of SE. These types of platforms provide several benefits across the full spectrum of care. By focusing on the healthcare network, we identified three stages of the customer experience. First, the SE acts at the pre-purchase stage with the customer request, which may refer to a search for the nearest available vehicle for an immediate intervention or to book a vehicle for a specific future date and time. The first relevance of value co-creation is demonstrated by the SE-based platform that can provide three main services, specifically, (1) non-emergency medical transport (in case of resignation, hospitalisation and transfers), (2) disabled transport (to request a vehicle approved for people with disabilities) or (3) a home-care service (to book an intervention at home by a health specialist). Usually, a platform-owned touchpoint (e.g. tablets and touchscreen devices) is provided in the intermediary centre structure. Once the customer chooses the desired service, we identified the reliable services to extract useful data for the intervention as follows: personal information; the customer's telephone number, to which the SE platform sends a text message with information to track the carrier's GPS position in real time; a service evaluation questionnaire; and the customer's email address so that he/she can receive a summary of the reservation and the final invoice. As affirmed by Saluber's founder, "Our mission is inspired performance across broad indicators of quality, safety and customer experience during his journey".

These effects contribute to the co-creation of value at the micro level. Furthermore, the sharing economy allows the actors to make the data of the intervention available (Figure 1) and furnishes the customer with information on the most appropriate vehicle for his/her intervention. By using SE-based platforms, customers can benefit from the traceability of the system through a geo-localisation-based system because they can input not only the starting address and destination address but also the preferred "stops" for the vehicle (with Saluber, there is a minimum threshold of $1 \mathrm{~h}$ to fulfil all customer activities). 
BPMJ

26,4

898

Figure 1.

Service experience through an SE platform in healthcare

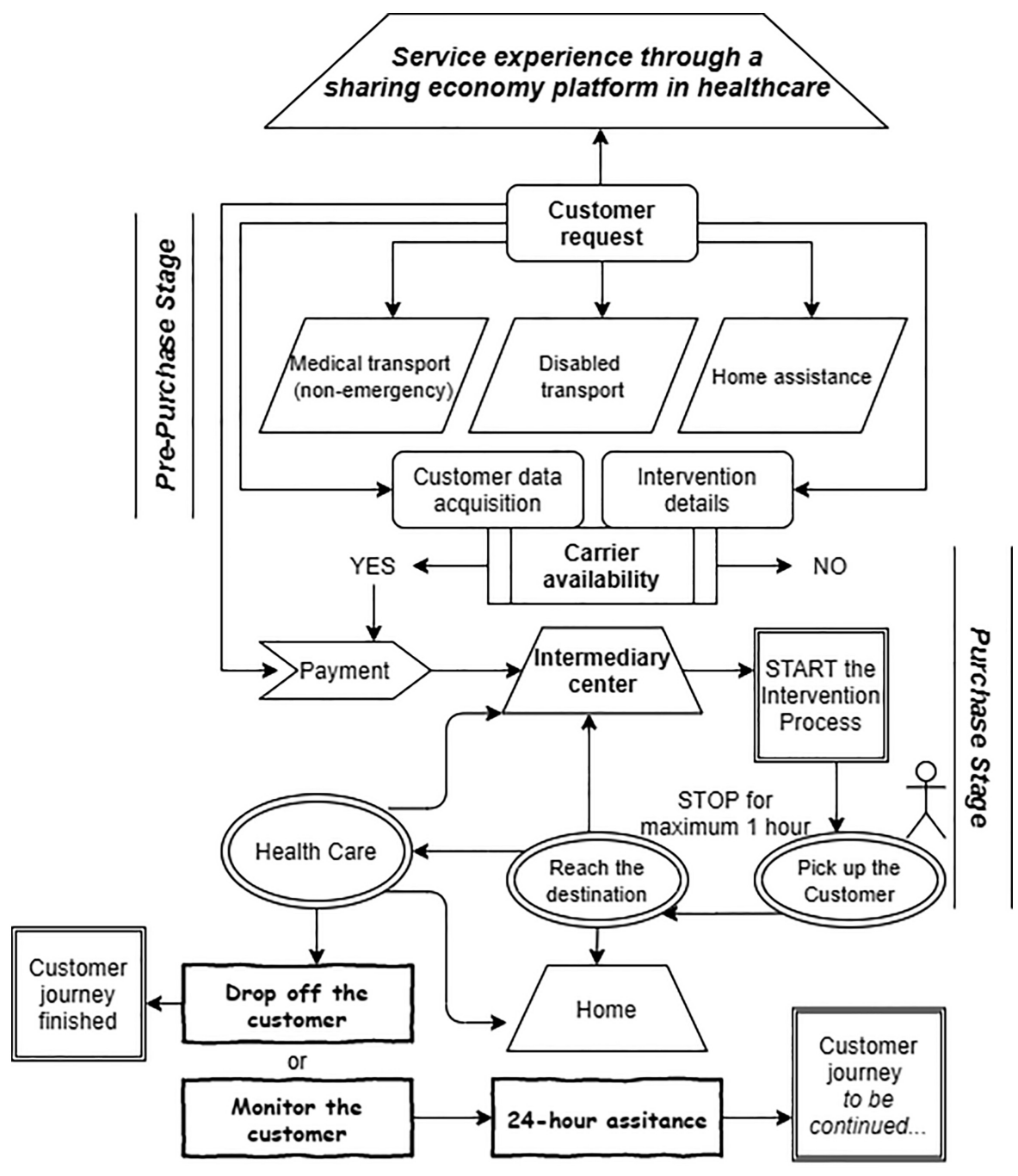

Post-Purchase Stage

Regarding the price element, the SE offers the most advantageous option for the requested transport, as detailed by the Saluber platform developer: "Saluber always guarantees the lowest price to its customers with attention to their needs. We allow intermediary centres to accept payment in three different ways: (1) credit card, for payments managed through the POS device provided on loan; 2) cash, with reference to payments taken over manually by the operator who takes care of the booking; and 3) debit, for payments for which the intermediary centre is responsible, indeed, in this case, the payment is managed with separate invoicing". 
At the purchase stage, when the payment is made, the SE-based platform can provide a countdown timer that indicates the time available for the carrier to accept or reject the customer's request. If the time available expires, the request is automatically rejected, and the system searches for another vehicle that can carry out the intervention. Thus, the customer experience in the SE-based network can improve in terms of the availability of information and the speed of services. Referring to the intervention process in the healthcare network, Saluber's key account manager said, "Saluber allows you to quickly identify the status of each intervention by using specific colours on the screen: blue for on-going interventions; orange for when the customer is arriving or leaving the intermediary centre; light blue for interventions that are scheduled for the day but that have not yet started; green for when the interventions are finished and therefore the customer has arrived at his destination; and grey if the intervention has been cancelled". Once the intervention starts, the carrier can communicate on the screen when the customer has reached the destination for which the service was requested.

Finally, the relevance of the SE is seen in the post-purchase stage when the customer decides whether he/she wants to be dropped off at his/her house or monitored, with 24-h assistance. Through this redesigned healthcare service, customers can benefit from the use of technological tools and can book an on-demand ride or schedule one based on their needs. As affirmed by a customer during his journey, "I'm able to monitor the status of each ride, from pick-up to drop-off, with the carrier's information in real time thanks to the traceability of the system".

\subsection{Effects of co-creation through a sharing economy at the meso level: the business processes for the network of healthcare organisations}

The recent pandemic explosion of COVID-19 is calling entire governments to redefine their approach to healthcare (http://www.euro.who.int/en/health-topics/health-emergencies/ coronavirus-covid-19/news/news/2020/3/who-announces-covid-19-outbreak-a-pandemic).

Furthermore, the current healthcare landscape is generating complicated data to manage; HOs use innovative solutions (e.g. a digital platform) to manage the vast array of data to extract the important pieces of information that can change their healthcare services and decision-making on their business processes. The portfolio of services offered by the SE platform positively impacts and transforms critical points in healthcare by using a unique network to create value for all the different stakeholders involved. As described on the official platform webpage (the brand-owned touchpoint), "Saluber helps to increase the volume of your business by becoming part of a network in continuous growth" https://www.saluber.me/ en/home.

By using the principles of an SE, the effect of co-creation is evident when the platform places into the network different structures (e.g. clinics and pharmacies) that do not provide the same services but may need to use mobility services and establish long-term business relationships. For instance, one of the key benefits is the possibility of offering blood transport, which is a frequently discussed topic among analysis laboratories in the Campania region, where there are central laboratories to which collection laboratories (small laboratories) need to transport test tubes. For this reason, the blood transport service is optimal and shows that transport is beneficial not only for customers but also for HOs. As affirmed by the director of a private clinic, "There is the possibility to increase your business by expanding the range of your services. There is also the possibility of networking with people who do not belong to the same group but [are] of different groups with whom there are collaborative relationships and activities. The benefits refer to the geo-localization of the service and the possibility to expand our business processes within a shared network".

The use of the SE in healthcare services was met with great enthusiasm by all the actors involved in the network. In Italy, the national health service is regionally based, with local 
BPMJ

26,4

900

authorities that offer the possibility to book the use of non-emergency medical transport some days before the established date through the intermediary centre. The weakness is that family doctors can make the prescription for only a single non-emergency medical transport, not for repetitive medical transports in "cycles". Thus, SE-based platforms could be a solution to the co-creation effects derived from the platform-owned touchpoints (e.g. a tablet used to book the service is on loan for free for one year). Intermediary centres make them available to customers to book and design their transport services. In this case, value creation occurs for the network, including intermediary centres, customers and SE companies. For these reasons, HOs' business processes can be redefined because the SE also offers the possibility of having mobility services available that can meet the needs of disabled customers or the elderly or infirm who do not have friends or relatives to accompany them.

Thus, participation in this network allows a diagnostic centre to redesign its business processes to increase process quality. Diagnostic centres usually do not offer transport services because they are concerned with performing laboratory tests (e.g. food allergy tests or breath tests) or diagnostic radiology (e.g. ultrasounds). HOs that participate in the SEbased network promote on their websites in the pre-purchase stage the option to transport customers. As affirmed by the administrative manager of an intermediary centre, "We have the possibility to offer a transport service for our customers. From the tablet, the request is routed to the smartphone of the carrier closest to the pick-up location. The service can be booked either live (directly, so 'I need an ambulance now') or scheduled on a date to be allocated for the scheduled intervention". The customer can use the legal and traceable transport service for several intermediary centres. Thus, a private clinic or a pharmacy offers this additional service, which provides them an advantage over other organisations.

\subsection{Effects of co-creation through a sharing economy at the macro level: the social service experience within the community}

An SE-based platform in a healthcare network can act as a social service organisation to support the customer in the post-purchase stage within the health community. Through back-end solutions that use vast amounts of data, SE-based platforms allow for action from a social services perspective. In fact, a first co-creation effect comes from the established network that can closely follow the citizens who belong to vulnerable groups to, thus, avoid unnecessary hospitalisations, which provides obvious economic savings and an improvement in the quality of life for the people in these categories. Once a customer returns home, Saluber identifies the availability of 24 -h services for specific cases. A detailed analysis by Saluber's founder is given as follows: "Saluber fits into the community with a great social role. With the increasing average age of the population, we have many elderly people who often have access to health services, who have disabilities, or who do not drive a car, or who have difficulties because their families cannot accompany them. Saluber puts the citizen/customer in the condition, through the intermediary centre where he must go for health services, to have easy access to a form of transport. The social role is very important, and traceability makes this service very secure and accessible".

The SE-based network provides healthcare professionals with a limited number of cars that can be used for home assistance. For instance, if a physiotherapist does not have a private car, the SE platform offers the practitioner a newly registered vehicle. "Saluber is also a wonderful social service experience. I used a Volkswagen Up for my first home assistance in the heart of Naples. It was an electric car with low environmental impact", said an interviewed nurse. Thus, the message launched by this renovated and innovative scenario is the following: "I will protect your health and the health of the planet". Other related evidence emerged from the key account manager: "We offer daily pampering that others do not offer, and that is why our customers are loyal. I will never see a person as a number, we see people as 
individual entities. We collect data. If you use the service a second time, I know who you are, what your name is, what pathology you have and what treatment plan you follow, who is the person who accompanies you, etc. If I collect data, I know the person very well and I can personalize the service based on the individual customer".

Another key relevant factor that testifies to the social role in the post-purchase stage within the community is the installation of specific measures to monitor each customer or offering psychological assistance to improve the customer's social life. An SE-based platform can link clients to community services to offer a support program and social care in the cases in which the disease can affect the emotional aspect of the customer. Value co-creation derives from monitoring the real-time data of customers' clinical and social practices with two primary benefits: first, clinics can suggest an $a d$ hoc advice to customers, and second, they can still creatively think of organising future social needs in an effective way. The aim is to expand the journey beyond the intermediary centres' walls (e.g. clinics, pharmacies or points of interest) and following customers with social care $24 \mathrm{~h}$ or helping them to enter into social service organisations.

Among other factors, we identified that this form of interaction includes increased investment in the field and an effective co-modality in the creation of innovation networks that promote the well-being of all actors within the community (Figure 1).

\section{Discussion and implications}

Digitalisation is generating a rethinking of organisations' strategies and practices to co-create value with their customers in many service industries (Verma et al., 2012; Lenka et al., 2017; Mele et al., 2018; Ramaswamy and Ozcan, 2018) and especially in healthcare (Omachonu and Einspruch, 2010; Iyawa et al., 2016; Wang and Hajli, 2017). Our case study is a good example of a customer-centric innovation in healthcare. As shown in the findings, the implementation of a strategic touchpoint with an SE-based platform has re-designed the total service experience for customers and created positive impacts for the entire network and the local community. These findings show how the SE has a potential to create and co-create value at different levels (micro, meso and macro).

We derived a multilevel model that shows how an SE redesigns service experiences and creates value in a healthcare network. As illustrated in the figure below (Figure 2), first, the creation of a digital SE-based platform created value for the customers (micro level) in terms of shorter waiting times, personalised assistance and a seamless experience. This application allows for the efficient management of booking requests so that people receive feedback in real time. This aspect is particularly relevant in a context such as southern Italy, where public services are generally ineffective. Particularly, the healthcare system in the Campania region

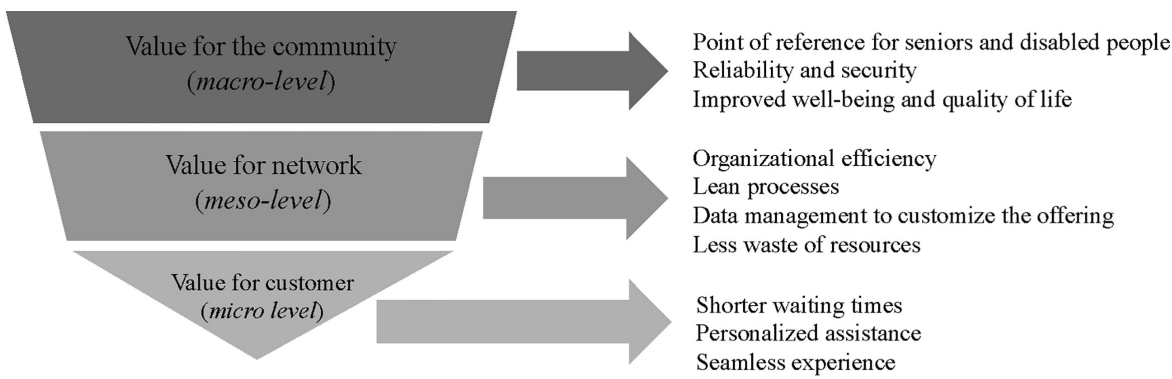

Figure 2. Re-designing the service experience in the value co-creation process: the proposed multilevel model

Source(s): Authors' research

\author{
Service \\ experience \\ in value \\ co-creation
}

901 
BPMJ

26,4

902

is rather limited in terms of structures and services due to the scarcity of the resources assigned to the region by the national government [1]. Therefore, not all citizens are efficiently served by the public system. In some cases, this situation represents an opportunity for companies to cover this market gap with private services, which may guarantee speed, customised assistance, safety and security for customers. Moreover, SE-based platforms also improve the interaction with the intermediary centre by allowing the creation of a one-on-one relationship with the customer to manage the best solution for him/her. Finally, the integrated services included in the platform allow the customer to be accompanied throughout the entire experience, from pick-up to home assistance (if needed).

Second, as is easily understandable, most of the value created for customers is derived from a re-design of the service experience process by taking advantage of the SE-based platform in terms of organisational efficiency, lean processes, data management and the waste of resources (meso level). First, the SE has facilitated communication among the actors in the network (providers, intermediary centres and customers) by reducing the time and costs of service management, which positively impacts the organisation, and by efficiently using resources with little or no waste. Moreover, a digital application allows the platform to keep the data on all the registered customers so that the intermediary centre can recognise a repeat customer through his/her history to offer a more efficient and personalised experience, improve customer satisfaction and encourage repurchase and word-of-mouth recommendations.

Moreover, the monitoring of data is crucial to improving the overall service design. Beyond the utilitarian value created for the customer and for the network, from this study despite its explorative stage - it is possible to also find social value for the local community (macro level). SE-based platforms such as Saluber are great examples of how to design a successful service experience by putting the customer first with an efficient integrated healthcare service (transportation and home assistance). Particularly in areas where services are inefficient, SE-based platforms have become a point of reference for seniors and people with disabilities. In Italy, for example, non-emergency transportation is provided by the public health system, but it is governed by very stringent rules. In fact, it must be requested by the family doctor who, by filling out the form, certifies the person's inability to travel by other means. Furthermore, the service must transfer the customer only to public hospitals and for exceptional events. There is no possibility to access this transport in case of periodic visits (e.g. chemotherapy cycles).

In this way, the efficiency created by these digital platforms may create value in terms of not only the reduction of time and costs but also customers' satisfaction and positive memories about the experience. Thus, from a long-term perspective, a positive brand image perceived by the community based on reliability and security as the main points of difference can help an SE platform and the network improve their reputation and competitive positioning. Furthermore, at the community level, this reality has a positive impact on the public's well-being because of the ability to count on an efficient, safe and customer needoriented service.

Based on the above-described findings and multilevel model, a series of theoretical and managerial implications can be developed. A newsworthy implication for scholars of customer centricity is that the proper management and exploitation of such technologies cannot occur without paying attention to the issues of management and the acquisition of data and information (Lemon and Verhoef, 2016; Lenka et al., 2017; Rindfleisch and Im, 2019). Customer-centred models initially showed large gaps at a practical level, but later, with the development of ICT solutions, they identified additional applications. This is in contrast to other business models, which did not see the customer precisely as a central focus but favoured the aspect of speed and efficiency of services, in the sense of being able to implement more processes in the shortest possible time. Through an SE, organisations and customers 
can exploit digital technologies, increase the interaction among resources and redefine business processes. Thus, this perspective efficiently influences the stages of the customer journey and experience (Lemon and Verhoef, 2016; Følstad and Kvale, 2018) and creates value. Therefore, co-creation in business contexts such as healthcare is also inevitably related to the service management literature.

Value co-creation processes in healthcare services involve various actors with different backgrounds who are positioned at different levels (e.g. customers, physicians, nurses, etc.). With the present research study, we also provide policy and managerial implications from a different perspective on the service experience by exploring unusual practices during customers' care journey. As previously stated, non-emergency transportation is inefficient, and despite the importance of the healthcare service, it is a standardised and not customer-oriented service because it implies long and difficult processes. Instead, health is the most important human right, so even non-emergency transportation should be more oriented to the customer's needs in terms of real-time usefulness, efficiency and assistance to guarantee social care, above all in a public healthcare system. The recent attempt of some worldwide private companies such as Uber Health, Lyft and Saluber is going to overcome this gap. Moreover, to respect health as a human right, in public healthcare systems such as Italy's, companies like Saluber aim to affiliate with the national healthcare system to ensure their services even to the people who cannot afford to pay.

From a managerial perspective, private clinics or pharmacies could expand their portfolio of services by offering mobility services to their customers. A company that has a vehicle fleet for particular care (ambulances or vehicles for disabled transport) could utilise their vehicles more frequently in this type of healthcare network in a cost-effective way. For these reasons, digital platforms based on the principles of the SE transform how organisations offer their products/services to transfer value. The actors involved in the healthcare network must monitor the dynamic role of digital technologies, identify customer needs and allow companies to respond to their requests while avoiding delays. This approach shows the great opportunities for ICT solutions within these business processes in service contexts such as healthcare.

\section{Conclusions}

The theoretical background and the case study analysis emphasise the magnitude of SE platforms as a touchpoint to innovate towards a customer-centric perspective in healthcare. In particular, this research, despite its explorative nature, demonstrates how an SE-based platform can create and co-create value at different levels. Therefore, firms should seriously consider an assessment of their management processes to see if they are oriented towards value co-creation (Vargo and Lusch, 2004; Mele et al., 2018; Ramaswamy and Ozcan, 2018). This research that demonstrates the implementation of a digital platform does not represent an operational tool but a strategic touchpoint to improve the relationships between the firm and the customer, among firms in the network and between the firm and the community. Thus, the aim of this SE-based platform is to achieve high-quality performance that deepens and enhances users' understanding of the importance of facilitating interorganisational interaction in the healthcare system.

However, for the platform to represent a long-term competitive advantage, the implementation of the digital touchpoint must accompany a re-design of the management of the total customer experience, which comprises processes, tasks, roles and, above all, a specific cultural mind-set (Homburg et al., 2017). To date, the research and innovation in the field of technology has been abundant, which has led to the creation of new global markets and to the development of ICTs. The healthcare economy constitutes a rather unique range of 
BPMJ

26,4

904

adjacent business networks in which the main actors interact and compete in various areas of specialisation. In recent years, the healthcare sector has undergone some radical changes that have rapidly transformed the relationships among the reference players, which increases competition and reveals how HOs are increasingly involved in economic development processes.

Although the results of the current study have shed light on several important issues, some limitations need to be considered in future research, such as the ability to exchange knowledge with external partners. The SE-based approach has also exploited the creation of personalised data, but the lack of knowledge not only of customers but also of health system operators creates stagnation in the system that prevents it from reacting to changes and new needs among the population. Future research may use surveys from a demand-side perspective to measure the value created for customers and the community in terms of satisfaction and experience compared to the use of public services and the willingness to recommend the service to relatives and friends. Moreover, a further interesting study might compare the value co-creation effects of SE-based platforms in different countries starting with the assessment of the national healthcare system.

For this reason, the evolution, changes and further advantages that these technologies entail, in addition to those already listed, could be the subject of future management studies.

\section{Note}

1. The current scarce resources for the regional healthcare system are due to regional budget overexpenditures in the previous years.

\section{References}

Alam, I. (2006), "Removing the fuzziness from the fuzzy front-end of service innovations through customer interactions", Industrial Marketing Management, Vol. 35 No. 4, pp. 468-480.

Anderson, L., Ostrom, A.L., Corus, C., Fisk, R.P., Gallan, A.S., Giraldo, M. and Shirahada, K. (2013), "Transformative service research: an agenda for the future", Journal of Business Research, Vol. 66 No. 8, pp. 1203-1210.

Ardley, B. and McManus, J. (2019), “The relationship between innovation and the co-creation process", Journal of Management Services, Vol. 63 No. 1, pp. 1-5.

Bansal, P., Smith, W.K. and Vaara, E. (2018), "New ways of seeing through qualitative research", Academy of Management Journal, Vol. 61 No. 4, pp. 1189-1195.

Barile, S., Saviano, M. and Polese, F. (2014), "Information asymmetry and co-creation in health care services", Australasian Marketing Journal (AMJ), Vol. 22 No. 3, pp. 205-217.

Belk, R. (2013), "Extended self in a digital world", Journal of Consumer Research, Vol. 40 No. 3, pp. $477-500$.

Bouncken, R.B. and Reuschl, A.J. (2018), "Coworking-spaces: how a phenomenon of the sharing economy builds a novel trend for the workplace and for entrepreneurship", Review of Managerial Science, Vol. 12 No. 1, pp. 317-334.

Braun, V. and Clarke, V. (2006), "Using thematic analysis in psychology", Qualitative Research in Psychology, Vol. 3 No. 2, pp. 77-101.

Breidbach, C.F. and Maglio, P.P. (2016), "Technology-enabled value co-creation: an empirical analysis of actors, resources, and practices”, Industrial Marketing Management, Vol. 56, pp. 73-85.

Brodie, R., Fehrer, J., Jaakkola, E. and Conduit, J. (2016), "From customer to actor engagement: exploring a broadened conceptual domain”, European Marketing Academy Conference, Oslo.

Carbonell, P., Rodriguez-Escudero, A.I. and Pujari, D. (2009), "Customer involvement in new service development: an examination of antecedents and outcomes", Journal of Product Innovation Management, Vol. 26 No. 5, pp. 536-550. 
Chesbrough, H. (2017), "The Future of open innovation: the future of open innovation is more extensive, more collaborative, and more engaged with a wider variety of participants", Research-Technology Management, Vol. 60 No. 1, pp. 35-38.

Dreyer, B., Lüdeke-Freund, F., Hamann, R. and Faccer, K. (2017), "Upsides and downsides of the sharing economy: collaborative consumption business models' stakeholder value impacts and their relationship to context”, Technological Forecasting and Social Change, Vol. 125, pp. 87-104.

Eisenhardt, K.M. (1989), "Building theories from case study research", Academy of Management Review, Vol. 14 No. 4, pp. 532-550.

Ferraresi, M. and Schmitt, B.H. (2006), Marketing Esperienziale, Franco Angeli, Milano.

Følstad, A. and Kvale, K. (2018), "Customer journeys: a systematic literature review", Journal of Service Theory and Practice, Vol. 28 No. 2, pp. 196-227.

Frankenberger, K., Weiblen, T., Csik, M. and Gassmann, O. (2013), "The 4I-framework of business model innovation: a structured view on process phases and challenges", International Journal of Product Development, Vol. 18 Nos 3-4, pp. 249-273.

Forlizzi, J. and Ford, S. (2000), "The building blocks of experience: an early framework for interaction designers", Proceedings of the 3rd conference on Designing Interactive Systems: Processes, Practices, Methods, and Techniques, pp. 419-423.

Gummesson, E. (2008), "Extending the service-dominant logic: from customer centricity to balanced centricity", Journal of the Academy of Marketing Science, Vol. 36 No. 1, pp. 15-17.

Gummesson, E. and Mele, C. (2010), "Marketing as value co-creation through network interaction and resource integration”, Journal of Bussiness Market Management, Vol. 4 No. 4, pp. 181-198.

Habibi, M.R., Davidson, A. and Laroche, M. (2017), "What managers should know about the sharing economy”, Business Horizons, Vol. 60 No. 1, pp. 113-121.

Hashem, I.A.T., Chang, V., Anuar, N.B., Adewole, K., Yaqoob, I., Gani, A. and Chiroma, H. (2016), "The role of big data in smart city", International Journal of Information Management, Vol. 36 No. 5 , pp. 748-758.

Holbrook, M.B. and Hirschman, E.C. (1982), "The experiential aspects of consumption: consumer fantasies, feelings, and fun”, Journal of Consumer Research, Vol. 9 No. 2, pp. 132-140.

Homburg, C., Jozić, D. and Kuehnl, C. (2017), "Customer experience management: toward implementing an evolving marketing concept", Journal of the Academy of Marketing Science, Vol. 45 No. 3, pp. 377-401.

Huang, M.H. and Rust, R.T. (2017), “Technology-driven service strategy”, Journal of the Academy of Marketing Science, Vol. 45 No. 6, pp. 906-924.

Iyawa, G.E., Herselman, M. and Botha, A. (2016), "Digital health innovation ecosystems: from systematic literature review to conceptual framework", Procedia Computer Science, Vol. 100, pp. 244-252.

Kannan, P.K. and Li, H. (2017), "Digital marketing: a framework, reviews and research agenda", International Journal of Research in Marketing, No. 1, pp. 22-45.

KPMG (2018), "The normal is the new normal”, available at: https:/home.kpmg/ng/en/home/insights/ 2018/08/No-normal-is-the-new-normal.html.

Länsisalmi, H., Kivimäki, M., Aalto, P. and Ruoranen, R. (2006), "Innovation in healthcare: a systematic review of recent research", Nursing Science Quarterly, Vol. 19 No. 1, pp. 66-72.

Lemon, K.N. and Verhoef, P.C. (2016), "Understanding customer experience throughout the customer journey", Journal of Marketing, Vol. 80 No. 6, pp. 69-96.

Lenka, S., Parida, V. and Wincent, J. (2017), "Digitalization capabilities as enablers of value co-creation in servitizing firms", Psychology and Marketing, Vol. 34 No. 1, pp. 92-100.

Mele, C., Spena, T.R. and Peschiera, S. (2018), "Value creation and cognitive technologies: opportunities and challenges", Journal of Creating Value, Vol. 4 No. 2, pp. 182-195. 
BPMJ

26,4

906

Meredith, J. (1998), "Building operations management theory through case and field research", Journal of Operations Management, Vol. 16 No. 4, pp. 441-454.

Miller, S.R. (2016), "First principles for regulating the sharing economy", Harvard Journal on Legislation, Vol. 53, p. 147.

Mills, A.J., Durepos, G. and Wiebe, E. (Eds) (2009), Encyclopedia of Case Study Research, Sage Publications, London.

Munoz, P. and Cohen, B. (2017), "Mapping out the sharing economy: a configurational approach to sharing business modeling”, Technological Forecasting and Social Change, Vol. 125, pp. 21-37.

Nadeem, W., Juntunen, M., Shirazi, F. and Hajli, N. (2020), "Consumers' value co-creation in sharing economy: the role of social support, consumers' ethical perceptions and relationship quality", Technological Forecasting and Social Change, Vol. 151, p. 119786.

Omachonu, V.K. and Einspruch, N.G. (2010), "Innovation in healthcare delivery systems: a conceptual framework", The Innovation Journal: The Public Sector Innovation Journal, Vol. 15 No. 1, pp. 1-20.

O'Hern, M. and Rindfleisch, A. (2010), "Customer co-creation: a typology and research agenda", in Review of Marketing Research, Emerald Group Publishing, Vol. 6, pp. 84-106.

Payne, A.F., Storbacka, K. and Frow, P. (2008), "Managing the co-creation of value", Journal of the Academy of Marketing Science, Vol. 36 No. 1, pp. 83-96.

Prebensen, N.K. and Foss, L. (2011), "Coping and co-creating in tourist experiences", International Journal of Tourism Research, Vol. 13 No. 1, pp. 54-67.

Prebensen, N.K., Vittersø, J. and Dahl, T.I. (2013), "Value co-creation significance of tourist resources", Annals of Tourism Research, Vol. 42, pp. 240-261.

Ramaswamy, V. and Ozcan, K. (2016), "Brand value co-creation in a digitalized world: an integrative framework and research implications", International Journal of Research in Marketing, Vol. 33 No. 1, pp. 93-106.

Ramaswamy, V. and Ozcan, K. (2018), "What is co-creation? An interactional creation framework and its implications for value creation”, Journal of Business Research, Vol. 84, pp. 196-205.

Ranjan, K.R. and Read, S. (2016), "Value co-creation: concept and measurement", Journal of the Academy of Marketing Science, Vol. 44 No. 3, pp. 290-315.

Richardson, A. (2010), "Using customer journey maps to improve customer experience", Harvard Business Review, Vol. 15 No. 1, pp. 2-5.

Rindfleisch, A. and Im, S. (2019), "Enhancing customer centricity via 3D printing", in Handbook on Customer Centricity, Robert Palmatier, Christine Moorman, and Ju-Yeon Lee, (Eds), Edward Elgar, New York.

Robbins, D.A., Curro, F.A. and Fox, C.H. (2013), "Defining patient-centricity: opportunities, challenges, and implications for clinical care and research", Therapeutiv Innovation and Regulatory Science, Vol. 47 No. 3, pp. 349-355.

Romero, D. and Molina, A. (2011), "Collaborative networked organisations and customer communities: value co-creation and co-innovation in the networking era", Production Planning and Control, Vol. 22 Nos 5-6, pp. 447-472.

Sánchez-Fernández, R. and Iniesta-Bonillo, M.Á. (2007), "The concept of perceived value: a systematic review of the research", Marketing Theory, Vol. 7 No. 4, pp. 427-451.

Shah, D., Rust, R.T., Parasuraman, A., Staelin, R. and Day, G.S. (2006), "The path to customer centricity", Journal of Service Research, Vol. 9 No. 2, pp. 113-124.

Sheth, J.N., Sisodia, R.S. and Sharma, A. (2000), "The antecedents and consequences of customercentric marketing", Journal of the Academy of Marketing Science, Vol. 28 No. 1, pp. 55-66.

Skaria, R., Satam, P. and Khalpey, Z. (2020), "Opportunities and challenges of disruptive innovation in medicine using artificial intelligence", The American Journal of Medicine, in press. 
Tellis, G.J. and Gaeth, G.J. (1990), "Best value, price-seeking, and price aversion: the impact of information and learning on consumer choices", Journal of Marketing, Vol. 54 No. 2, pp. 34-45.

Troisi, O., Carrubbo, L., Maione, G. and Torre, C. (2016), "The more, the merrier: co-working as practical expression of value co-creation in sharing economy", XXVI RESER Conference, pp. 1130-1144.

Service
experience
in value
co-creation

907

Vargo, S.L. and Lusch, R.F. (2008), "From goods to service (s): divergences and convergences of logics”, Industrial Marketing Management, Vol. 37 No. 3, pp. 254-259.

Vargo, S.L. and Lusch, R.F. (2016), "Institutions and axioms: an extension and update of servicedominant logic", Journal of the Academy of Marketing Science, Vol. 44 No. 1, pp. 5-23.

Vargo, S.L., Maglio, P.P. and Akaka, M.A. (2008), "On value and value co-creation: a service systems and service logic perspective", European Management Journal, Vol. 26 No. 3, pp. 145-152.

Verleye, K. (2015), "The co-creation experience from the customer perspective: its measurement and determinants", Journal of Service Management, Vol. 26 No. 2, pp. 321-342.

Verma, R., Teixeira, J., Patrício, L., Nunes, N.J., Nóbrega, L., Fisk, R.P. and Constantine, L. (2012), "Customer experience modeling: from customer experience to service design", Journal of Service Management, Vol. 23 No. 3, pp. 362-376.

Voorhees, C.M., Fombelle, P.W., Gregoire, Y., Bone, S., Gustafsson, A., Sousa, R. and Walkowiak, T. (2017), "Service encounters, experiences and the customer journey: defining the field and a call to expand our lens", Journal of Business Research, Vol. 79, pp. 269-280.

Wang, Y. and Hajli, N. (2017), "Exploring the path to big data analytics success in healthcare", Journal of Business Research, Vol. 70, pp. 287-299.

Wilhelms, M.P., Merfeld, K. and Henkel, S. (2017), "Yours, mine, and ours: a user-centric analysis of opportunities and challenges in peer-to-peer asset sharing", Business Horizons, Vol. 60 No. 6, pp. 771-781.

Yang, S., Song, Y., Chen, S. and Xia, X. (2017), "Why are customers loyal in sharing-economy services? a relational benefits perspective", Journal of Services Marketing, Vol. 31 No. 1, pp. 48-62.

Yim, C.K.B., Chan, K.W., Caleb, H.T. and Leung, F.F. (2019), "Customer centricity and customer cocreation in services: the double-edged effects", Handbook on Customer Centricity, Edward Elgar Publishing, New York.

Yin, R.K. (2013), "Validity and generalization in future case study evaluations", Evaluation, Vol. 19 No. 3, pp. 321-332.

Yin, R.K. (2017), Case Study Research and Applications: Design and Methods, Sage publications, Thousand Oaks.

Zainuddin, N., Russell-Bennett, R. and Previte, J. (2013), "The value of health and wellbeing: an empirical model of value creation in social marketing", European Journal of Marketing, Vol. 47 No. 9, pp. 1504-1524.

Zeithaml, V.A. (1988), "Consumer perceptions of price, quality, and value: a means-end model and synthesis of evidence", Journal of Marketing, Vol. 52 No. 3, pp. 2-22.

Zhang, T.C., Jahromi, M.F. and Kizildag, M. (2018), "Value co-creation in a sharing economy: the end of price wars?", International Journal of Hospitality Management, Vol. 71, pp. 51-58.

Zomerdijk, L.G. and Voss, C.A. (2010), "Service design for experience-centric services", Journal of Service Research, Vol. 13 No. 1, pp. 67-82.

\section{Further reading}

Seawright, J. and Gerring, J. (2008), "Case selection techniques in case study research: a menu of qualitative and quantitative options", Political Research Quarterly, Vol. 61 No. 2, pp. 294-308. 
BPMJ

26,4

908

\begin{abstract}
About the authors
Francesco Schiavone is an Associate Professor in Management at Parthenope University of Naples, Italy, since 2016. He received the $\mathrm{PhD}$ degree in network economics and knowledge management from the Ca' Foscari University of Venice (Italy) in 2006. He is also an Affiliated Professor in Innovation Management at Paris School of Business and a Visiting Professor at IESEG School of Management (France). In April 2017, Professor Schiavone has been habilitated as a Full Professor in Management by MIUR (Italian Ministry of Education and Research). Currently, his main research areas are technology management, strategic innovation and healthcare management and innovation. Francesco Schiavone is the corresponding author and can be contacted at: francesco.schiavone@uniparthenope.it

Daniele Leone is a Research Fellow at Parthenope University of Naples, Italy. He received his Doctoral degree in Management from the University of Naples Federico II in February 2019. In 2017, he was a Visiting Scholar at the Norwich Business School, University of East Anglia, Norwich, UK. In 2015, he received the Master's degree in International Marketing and Management from Parthenope University, Naples, Italy. He is also a member of the editorial board of the International Journal of Globalization and Small Business. His main research areas are innovation management, crowdfunding and healthcare management.

Annarita Sorrentino is an Assistant Professor in Marketing at the Department of Management and Quantitative Studies of University of Naples Parthenope, where she is teaching customer experience management. Annarita has been visiting scholar at Middlesex University and at the Leeds Beckett University, where she has conducted her research on consumer behavior in tourism and hospitality. Her main research areas are consumer experience, tourism marketing and service management.

Alessandro Scaletti is an Associate Professor in Accounting at Parthenope University of Naples, Italy. His main research areas are technology management, smart cities and healthcare economics.
\end{abstract}

For instructions on how to order reprints of this article, please visit our website:

www.emeraldgrouppublishing.com/licensing/reprints.htm

Or contact us for further details: permissions@emeraldinsight.com 